\title{
Stepping Back to Move Forward: Assessing the Quality of Maternity Health Services of Kathmandu Valley
}

\author{
Kiran Bhetwal ${ }^{1}$
}

\begin{abstract}
This paper is the assessment of the women's perception towards the quality of services they received during their maternity time and examining their level of satisfaction with the intention to revisit the same hospital for future services. Primary quantitative data through the distribution of questionnaire from 150 respondents using convenience sampling from five hospitals viz Nagarik Hospital, Teaching Hospital, Thapathali Hospital, KMC and Patan Hospital were collected. Majorities of the respondent were satisfied enough to return to the hospital and would happily recommend others as well. This study found that human and physical resources have the lowest average. Implying that most of the respondent felt that it was the most important factor while choosing the hospital followed by privacy, cognition, physical abuse, denial of requested care, confidentiality, emotional support, involvement of family member and finally respect, dignity and equity scores last. It means that no matter which hospital respondent went they found it most obvious to be treated with respect. It clearly shows the reason on why the hospital is investing more on the infrastructure rather than innovating and delivering higher service quality. On the serious note, a case of physical and verbal abuse also came into light during the investigation. Not much of research based policies are seen to protect such critical case.
\end{abstract}

Keywords: Primary data, descriptive and inferential statistics, quality of care, maternity health

\section{Introduction}

Like any other service industries, customer satisfaction with service quality and retention remains critical issue in health care services. With increase in consumerism and availability of choice, today's patient's expectations have changed drastically. Indeed, today's patient are more informed and would not

1 Ms. Bhetwal is an MBA graduate of Ace Institute of Management, Pokhara University. Email: kiranbhetwal@gmail.com 
hesitate to switch to alternative health care if they do not get the level of satisfaction expected by them. Thus assessing and evaluating health care quality is crucial for consumers, health care providers and society itself (Aryal \& Koirala, 2019). Based on the findings, researcher have revealed the presence of few cases of verbal abuse and a case where one of the respondent shared that she was physically abused as well.And, these cases were from reputed hospitals of Kathmandu Valley which made researcher think of possible behavior/ situation that other women goes through while giving birth on other average hospitals of Kathmandu. So, researcher thought of doing this research to know the level of respect shown during child birth and also to see whether they still revisit the hospital after receiving ill treatment.

It can be seen that numerous study has been done on the determinants of quality and its retention on western side of the world undertaking various categories like HIV-positive women in Nigeria, improvement intervention in Northen Ghana.But the research on the same in the context of Nepal is almost non-existence. So this paper is expected to fill the gap. The research is focused to improve the quality of the women as women suffer from mental health conditions such as depression, anxiety and trauma and face more barriers accessing healthcare services. This is achieved through identification of maternity service quality determinants and examining that with retention of that customer. The list of research mentioned at literature review have shown the importance of good quality service for successful child birth but it lacks to show the relationship the quality of service has on the retention of customers. Further the variables that affects the quality in Nepal is different than that of international scenario which shows gap in implementation of findings. Hence, this research tries to bridge this gap and find answers to the objectives generated.

In the context of Nepal has committed to achieving the Millennium Development Goal Five (MDG-5) to improve maternal health, with the target to reduce maternal mortality ratio (MMR) by three-quarter by 2015. Between 1996 and 2006, Nepal nearly halved its MMR, from 539 deaths per 100,000 live births to 281, according to the Demographic and Health Survey, based on Nepal Demographic and Health Survey 2011.According to the Service Tracking Survey 2013 of Nepal Health done by Ministry of Health and Population, Sector Program II found that $11 \%$ of the maternity clients felt that they had been mistreated because of their poor economic condition and due to their caste or ethnicity.A 2012 UN report estimated the 2010 MMR at 170. National Policy on Skilled Birth Attendants done by department of helath services, showed the Policy on Skilled Birth Attendants specifically identifies the importance of skilled birth attendants (SBAs) at every birth. And DHS, Annual Report 2015 showed institutional delivery has been promoted by 
Nepal Government with free maternity services and incentive packages as measures of reducing MMR which is now $57 \%$.

However, the trust towards hospital is the increasing factor which is not seems to be analyzed well by the hospitals to increase the satisfaction of the customers with respect to international standards. Still the flaws identified by the study have wide consequences on the patient's experience of the quality of healthcare delivered. For effective service it requires collaborated efforts by all stakeholders, especially the hospital administrative committee and attending staffs. It has raised the questions such as does the behavior/ treatment done at the delivery period influence the revisit decision? What are the major determinants of choosing the hospital? What is current delivery status in major hospitals of Kathmandu Valley? Therefore, the present study sought to answer the following objectives i) to study factors influencing in selection of hospital ii) to examine their relationship between experience of care and retention and iii) to analyze the current status of the delivery condition in major hospitals of Kathmandu Valley.

Hospital brand image indeed serves as a lead factor in enhancing service quality, patient satisfaction, and patient loyalty. In addition, the results imply that the path from service quality to patient satisfaction is a key avenue for the impact of hospital brand image on patient loyalty. Consequently, proposing that hospital managers should strive to create and maintain the positive hospital brand image in order to enhance service quality, patient satisfaction, and loyalty $(\mathrm{Wu}, 2011)$. Another research done by World Health Organization at Geneva on reviewing maternal deaths and complications to make pregnancy safer, it is identified that over $80 \%$ of these deaths could be prevented or avoided through timely interventions proven to be effective and affordable.

According to the longitudinal survey done in Nepal, perception of quality differed significantly by types of health facility used for delivery. They rated lowest the supplies and equipment in birth centres and the amenities and interpersonal aspects in the public hospital. Accordingly, attention to these aspects is needed to improve the quality (Karkee, Lee, \& Pokharel, 2014).The RMC rights of women are based on international human rights instruments including the Universal Declaration of Human Rights; Universal Declaration on Bioethics and Human Rights; International Covenant on Economic, Social and Cultural Rights; Convention on the Elimination of All Forms of Discrimination Against Women; Declaration of the Elimination of Violence Against Women; and the United Nations Fourth World Conference on Women, Beijing.

The seven rights of childbearing mothers correspond with seven categories of abuse and disrespect identified by Bowser and Hill. The seven rights include (i) 
Freedom from harm and ill treatment (ii) Right to information, informed consent and refusal (iii) Confidentiality, privacy (iv) Dignity, respect (v) Equality and equitable care (vi) Right to timely healthcare and (vii) Self-determination, and freedom from coercion. The categories of disrespect and abuse that corresponds with the above mentioned rights are (i) Physical abuse (ii)Non-consented care (iii) Non-confidential care (iv) Non-dignified care (v) Discrimination based on specific attributes (vi) Abandonment or denial of care (vii) Detention in facilities. Another research done in Kenya to explore the prevalence of disrespect and abuse during childbirth found out that One out of five women experienced feeling humiliated during labor and delivery. Six categories of D\&A during childbirth in Kenya were reported. Understanding the prevalence of D\&A is critical in developing interventions at national, health facility and community levels to address the factors and drivers that influence D\&A in facilities and to encourage clients' future facility utilization.

Rest of the study has arranged as follows, the second section has incorporate research methodology used to evaluate and analyze and forth section incorporates result and discussion derived from both descriptive as well as inferential statistics. Finally, last part concludes the study.

\section{The Methodology}

This section of the analysis deals with the descriptive analysis of the data collected through the questionnaire. It describes the basic features of the data in the study. They provide the simple summaries about the samples and the measures.

\section{The Conceptual Framework}

The conceptual framework of this study has been drafted by replicating the genuine model of the paper "A framework for the evaluation of quality of care in maternity services" (2000). As seen on the figure attached; there are two possible functions of this framework. First being as a tool by which it helps to structure a situation analysis review of the quality of care provided at a facility, and experienced and perceived by its clients, actual and potential. And the second issue, being a tool by which to improve the quality of care through the ongoing critical examination of activities. In analysis, where care falls short, we can find the areas to improve and implement the change. 
Figure 1: The Conceptual Framework

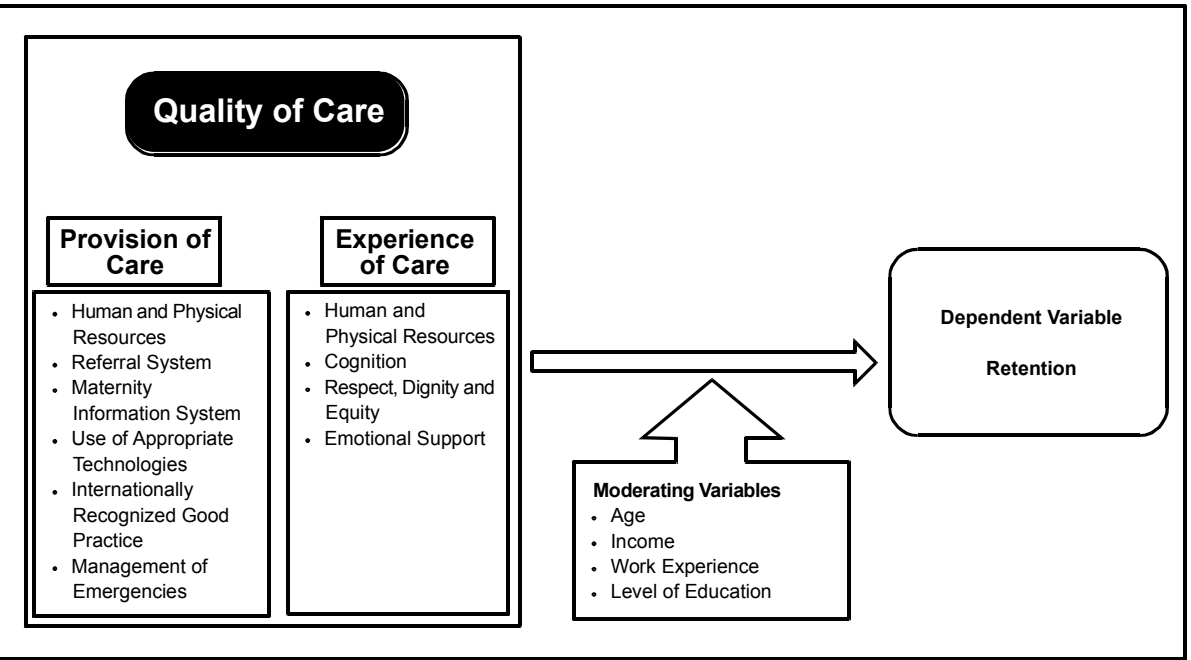

Source: Modified from Hulton et al. (2000)

The variable selection for this study is based on the conceptual framework. The dependent variable for this study is retention.Patient retention is defined as the strategy and tactics designed to keep patients enrolled in clinical trials, and encourage continuing the service of the particular hospital, basically preventing patients to "drop out" of the company's service. As a management background researcher, researcher wanted to know how the service quality affects the intention of the patient to revisit the hospital for future services. Hence, the reason why researcher chose retention as dependent variables.

The independent variable selections are Human and physical resources, Physical abuse, Cognition, Denial of requested care, Respect, dignity and equity, Emotional Support and Privacy and Confidentiality. Human resources and physical resources:A woman's experience of care relates not only to the quality and appropriateness of the maternity care she receives and her perception of the quality of that care, but also to her impression of the state of the infrastructure (the bed, sheets, food, toilets, actual contact time with qualified staff and so on).Physical abuse:This component refers whether woman is physically harmed or restrained; her needs for nutrition, elimination, movement, physical comfort and pain relief are met adequately; the newborn is kept warm in close contact with mother and is breastfed within one hour of birth.Cognition:Cognition relates to two specific experiences of care that is i) the extent to which a woman feels she understands what is happening and feels that her questions have been answered adequately and 
ii) whether she receives information in a form that she and her family understand and that she has the right to know.Denial of requested care:It refers that the woman is encouraged to call for help and responded immediately; never left alone and unattended and kept for long time before responding.Respect, dignity and equity:Respect, dignity and equity Fundamental differences exist in the status, power and culture of participants in the client-provider encounter. These interactions are rarely characterized by supportive relationships, more often expressing dissonance, inherent conflict and social disparities.Emotional Support: Fear; pain and anxiety may be increased by a mechanized clinical environment and unknown attendants, with potentially adverse effects on the progress of labor. A hospital environment, where separation of family members and rigid protocols are enforced is one of the factors believed to cause the high intervention rates during labor that are seen in many industrialized societies. Privacy and Confidentiality: This component includes that the woman's privacy is maintained during any examinations, procedures and childbirth and any information regarding her was kept confidential; or shared after her approval.Women:It refers to the postnatal women giving birth in Maternal and Neonatal Service Center (MNSC) unit of Paropakar Maternity and Women's Hospital.Besides dependent and independent variables, this study also observed the role of moderating variable. However, only income is taken as moderating variable because the researcher assumed that the earning of a person has or her partner is critical determinant to choose a hospital and also to react in a certain way on ill treatment faced during child birth, which researcher felt might affect the expectation of the mother the care providers. Though the age, level of education and work experience is also important but when it comes to the level of service quality one expects from the service provider, it is often directly proportionate to the amount of disposable income which gives client more options to switch the service provider.

To quantify these variables, Yes/No question, multiple choices, ranking scale and likert scale is used. Based on the variables, following hypotheses are made:

$\mathrm{H}_{01}$ : There is no significant relationship between human and physical resources and retention.

$\mathrm{H}_{02}$ : There is no significant relationship between cognition and retention.

$\mathrm{H}_{03}$ : There is no significant relationship between privacy received and retention.

$\mathrm{H}_{04}$ : There is no significant relationship between physical abuse and retention.

$\mathrm{H}_{05}$ : There is no significant relationship between denial of requested care and quality retention.

$\mathrm{H}_{06}$ : There is no significant relationship between confidentiality and retention. 
$\mathrm{H}_{07}$ : There is no significant relationship between level of emotional support received and retention.

$\mathrm{H}_{08}$ : There is no significant relationship between respect, dignity and equity and retention.

$\mathrm{H}_{09}$ : There is no significant relationship between income and retention.

Study Area and Data: The study is based on Kathmandu Valley where the population for this survey is five hospital's patients namely Nagarik Hospital, Teaching Hospital, Thapathali Hospital, KMC and Patan Hospital. Convenience sampling is done to select sample from these population. The primary data is collected through structured questionnaires following face-to-face interview. Each interview took around 20-25 minutes to clearly explain and record the response. The sample sizes of 150 patients are taken through convenient and judgmental sampling from hospitals. First, second or third time mothers who visited hospital for first vaccination of their baby, i.e. within 45 days of delivery, were asked by researcher to administer questionnaire.

The questionnaire consists of various types of questions such as single response questions, multiple response questions, ranking scale questions and likert scale. Validity and Reliability are the two crucial factors that play a vital role throughout the study, from designing of the study till examining the study. Internal consistency and reliability is also tested through likert scale. The Cronbach's Alpha coefficient for multiple likert scale is tested to ensure the validity and reliability of the research questions. The Cronbach alpha coefficient value for this study is 0.888 which is more than 0.6 hence the data collected is considered reliable and valid.

Descriptive research design is adopted where the primary data collected through the distribution of questionnaire. And the secondary data is obtained from various information sources like internet, books, newspaper, journals and articles. For analysis purpose SPSS and MS Excel are used. Since the study requires to know the relationship between variables for which the hypothesis testing, ANOVA, normality test, and correlation analysis are done so as to derive the inferential information that helps in obtaining the outcome of the study. Tables are used as the output of SPSS and are analyzed as per the data that is inputted.

\section{Result and Discussion}

The majority of the respondents lied between $15-25$ years i.e. $88 \%$ and just $12 \%$ lied between age group of 26-49 years. Initially data was divided as teenagers (14$19),(20-25),(26-35)$ and (36-45). The data was grouped in these two groups after the collection of primary data as majority of the respondent fell under 15-25 group.Out of 150 respondents, $43.3 \%$ of the study fell under intermediate or below 
educational level and $40 \%$ under graduate and $25 \%$ graduate level. May be this is the reason why majority of the respondents were homemaker i.e. $60 \%$ of them followed by service sector occupation with $35 \%$. 14\% of them do their own business most of them were engaged in apparel business or owned beauty parlor. And only $11 \%$ of them have agriculture as main occupation.59 of the respondent lies between three to five hundred thousand annual incomes categories where as just 2 of them earned below one hundred thousand. 45, 22 and 22 earned Rs. 500,000- 800,000, 100,000-300,000 and above 800,000 annually. Among 150 respondents, majorities of them feel that proper amount of care was given to them and that they were satisfied enough to return the hospital and also recommend other as well.

One of the objectives of the research was to find out the factors that influences in selection of hospital. This study identifies six elements related to the provision of care: human and physical resources; the referral system; management information system; the use of appropriate technologies; internationally recognized good practice; and the management of emergencies. Four aspects relating to women's experience of care are also identified namely; human and physical resources; cognition; respect, dignity and equity and emotional support.Looking at the rank given to the human and physical resources was ranked first followed by Privacy with mean of 4.05. Cognition ranks in third with mean of 4.13 that its Physical abuse that stands as fourth important factor to select the hospital with mean of 4.77. Denial of requested care is a fifth factor with mean of 5.09. Then it's the confidentiality that stands in sixth position with mean of 5.56 as an important factor in selection of hospital. Level of emotional support is in seventh position as important factor in selection of hospital. It means that the level in which they received the level of honesty and kindness and how well staffs were equipped and competent. Involvement of family member stands in eight positions with mean of 6.29. Respect, dignity and equity scores last with the mean of 6.68. and according to the response they find it most obvious that they will be treated with respect no matter which hospital they join.

It came that overall scenario was favorable as all the variables selected from which hypothesis generated was rejected showing significant relationship. Expect for the hypothesis showing relationship between denial of request and retention as respondent thinks that no hospital can exercise this as it has now become unethical.

\section{Inferential Analysis}

The correlation between confidentiality and retention is 0.116 , which means there is positive correlation between confidentiality that the medical team was group of expert and that the entire instrument used was properly sterilized with the level of 
retention. The corresponding p-value is 0.159 , which is more than level of significance $(\alpha)=0.01$, signifying that there is no significant relationship between confidentiality and retention, i.e. H06 is accepted. The researcher feels that looking at the Nepalese society, sharing of the personal medical condition is not much of a issue and Nepalese tends to share their own or their families or friends health condition as a normal conversation. Correlation is a statistical measure that indicates the extent to which two or more variables fluctuate together. This analysis is used to test the hypothesis of the study.

Table No.1: Correlation of Factors Influencing Retention and Experience of Care

\begin{tabular}{|c|c|c|c|c|c|c|c|c|c|c|}
\hline & $\mathrm{X} 1$ & $\mathrm{X} 2$ & $\mathrm{X} 3$ & $\mathrm{X} 4$ & $\mathrm{X} 5$ & $\mathrm{X} 6$ & $\mathrm{X} 7$ & $\mathrm{X} 8$ & X9 & $\mathrm{X} 10$ \\
\hline \multirow[t]{3}{*}{$\mathrm{X} 1$} & & $.561 * *$ & $.475 * *$ & $.442 * *$ & $-.170 *$ & $.164 *$ & $.191 *$ & $.594 * *$ & $.312 * *$ & $.555 * *$ \\
\hline & & 0 & 0 & 0 & 0.037 & 0.044 & 0.019 & 0 & 0 & 0 \\
\hline & & 150 & 150 & 150 & 150 & 150 & 150 & 150 & 150 & 150 \\
\hline \multirow[t]{3}{*}{$\mathrm{X} 2$} & & & $.318 * *$ & $.303 * *$ & $-.267 * *$ & 0.083 & $.347 * *$ & $.328 * *$ & $.250 * *$ & $.326 * *$ \\
\hline & & & 0 & 0 & 0.001 & 0.315 & 0 & 0 & 0.002 & 0 \\
\hline & & & 150 & 150 & 150 & 150 & 150 & 150 & 150 & 150 \\
\hline \multirow[t]{3}{*}{$\mathrm{X} 3$} & & & & $.417 * *$ & $-.243 * *$ & 0.068 & $.330 * *$ & $.365 * *$ & $.263 * *$ & $.451 * *$ \\
\hline & & & & 0 & 0.003 & 0.406 & 0 & 0 & 0.001 & 0 \\
\hline & & & & 150 & 150 & 150 & 150 & 150 & 150 & 150 \\
\hline \multirow[t]{3}{*}{$\mathrm{X} 4$} & & & & & $-.243 * *$ & 0.139 & $.378 * *$ & $.342 * *$ & 0.066 & $.417 * *$ \\
\hline & & & & & 0.003 & 0.09 & 0 & 0 & 0.423 & 0 \\
\hline & & & & & 150 & 150 & 150 & 150 & 150 & 150 \\
\hline \multirow[t]{3}{*}{$\mathrm{X} 5$} & & & & & & $-.175 *$ & $-.222 * *$ & $-.255 * *$ & $-.212 * *$ & $-.421 * *$ \\
\hline & & & & & & 0.032 & 0.006 & 0.002 & 0.009 & 0 \\
\hline & & & & & & 150 & 150 & 150 & 150 & 150 \\
\hline \multirow[t]{3}{*}{ X6 } & & & & & & & 0.123 & 0.043 & 0.096 & 0.116 \\
\hline & & & & & & & 0.133 & 0.599 & 0.243 & 0.159 \\
\hline & & & & & & & 150 & 150 & 150 & 150 \\
\hline \multirow[t]{3}{*}{ X7 } & & & & & & & & $.337 * *$ & $.284 * *$ & $.316 * *$ \\
\hline & & & & & & & & 0 & 0 & 0 \\
\hline & & & & & & & & 150 & 150 & 150 \\
\hline \multirow[t]{3}{*}{$\mathrm{X} 8$} & & & & & & & & & $.419 * *$ & $.529 * *$ \\
\hline & & & & & & & & & 0 & 0 \\
\hline & & & & & & & & & 150 & 150 \\
\hline \multirow[t]{2}{*}{ X9 } & & & & & & & & & & $.379 * *$ \\
\hline & & & & & & & & & & 0 \\
\hline $\mathrm{X} 10$ & & & & & & & & & & 150 \\
\hline
\end{tabular}


The table 1 shows the correlation matrix between different variables of correlation matrix.

** Correlation is significant at the 0.01 level (2-tailed).

* Correlation is significant at the 0.05 level (2-tailed).

Where,

$\mathrm{X} 1=$ Human and Physical resources

$\mathrm{X} 2=$ Privacy

$\mathrm{X} 3=$ Cognition

$\mathrm{X} 4=$ Physical abuse

X5 $=$ Denial of Requested care

$\mathrm{X} 6=$ Confidentiality

$\mathrm{X} 7=$ Level of emotional support

$\mathrm{X} 8=$ Respected, dignity and equity

$\mathrm{X} 9=$ Involvement of family member

$\mathrm{X} 10=$ Retention and satisfaction

Relationship of "Denial of Request" is positively correlated with all other nine variables namely Human and Physical resources, Cognition, Physical abuse, Confidentiality, Privacy, Level of emotional support, respect, dignity and equity and involvement of family member with value of $-.17,-.267,-.243,-.243,-.175$, $.222,-.255,-.212$ and -.421 respectively.

TableNo.2: Result of Hypotheses Testing

\begin{tabular}{|c|c|c|}
\hline Hypothesis & Statement & Status \\
\hline $\mathrm{H} 01$ & $\begin{array}{l}\text { There is no significant relationship between human/ physical } \\
\text { resources and retention. }\end{array}$ & Rejected \\
\hline $\mathrm{H} 02$ & $\begin{array}{l}\text { There is no significant relationship between level of privacy and } \\
\text { retention. }\end{array}$ & Rejected \\
\hline $\mathrm{H} 03$ & $\begin{array}{l}\text { There is no significant relationship between cognition and } \\
\text { retention. }\end{array}$ & Rejected \\
\hline H04 & $\begin{array}{l}\text { There is no significant relationship between physical abuse and } \\
\text { retention. }\end{array}$ & Rejected \\
\hline H05 & $\begin{array}{l}\text { There is no significant relationship between denial of requested and } \\
\text { retention. }\end{array}$ & Rejected \\
\hline H06 & $\begin{array}{l}\text { There is no significant relationship between confidentiality and } \\
\text { retention. }\end{array}$ & Accepted \\
\hline H07 & $\begin{array}{l}\text { There is no significant relationship between level of emotional } \\
\text { support and retention. }\end{array}$ & Rejected \\
\hline H08 & $\begin{array}{l}\text { There is no significant relationship between respected, dignity and } \\
\text { equity; and retention. }\end{array}$ & Rejected \\
\hline H09 & $\begin{array}{l}\text { There is no significant relationship between involvement of family } \\
\text { member and retention. }\end{array}$ & Rejected \\
\hline
\end{tabular}




\section{Concluding Remarks}

Researcher found out that there was a case of physical and verbal abuse prevalent in the maternity hospitals of Kathmandu valley. The case came in light during data collection that major reputed organization of the Kathmandu Valley. This poses a serious implication on the state that other women might suffer at other average hospitals questioning the status of the hospitals in valley and in Nepal itself.Expect for confidentiality all other variables have significant variables with the independent variables. Researcher feels that in Nepalese society it is found normal to share information personal medical condition with one another so maybe they felt that confidentiality was maintained in every hospital they were admitted to. The evidence of physical abuse was also seen questioning the status of the hospitals in other minor valley hospitals or others from various parts of Nepal.However, it can be seen that the trust towards hospital has increased though hospital has not been able to cater towards the increasing service expectation of the same customers with respect to the international standards that customers are aware of. Still the flaws identified by the study have wide consequences on the patient's experience of the quality of healthcare delivered but it can obviously be solved with joint effort of the hospital administrative committee and attending staffs like making the physical and human resources adequate enough to fulfill all the needs of the respondents ensuring the involvement of the family member a good experience which in turn will increase the good will of the hospital i.e. confidentiality.

\section{References}

Aryal, B., \& Koirala, R. (2019). Frequency of risk factors for coronary artery disease among cardiac patients at manmohan cardiothoracic vascular and transplant center, Nepal: Cross-sectional study. Journal of Asian Scientific Research, 9(3), 20.

Department of Health Services, F. H. (2006).National policy on skilled birth attendants. Kathmandu: Author.

Department of Health Services.(2015).Annual report. Kathmandu: Author.

Hulton, L., Matthews, Z., \& Stones, R. W. (2000).A framework for the evaluation of quality of care in maternity services.Highfield: University of Southampton.

Karkee, R., Lee, A. H., \& Pokharel, P. K. (2014). Women's perception of quality of maternity services: A longitudinal survey in Nepal. BMC Pregnancy and Childbirth. 
Ministry of Health and Population. (2011). Nepal demographic and health survey 2011. Kathmandu, Nepal

Service Tracking Survey. (2013). Nepal Health Sectoral Programme II. Retreieved from

http://www.nhssp.org.np/NHSSP Archives/monitoring/Service Tracking Surv ey_2013.pdf

United Nations. (2012). Nepal Achievements Report. Retrieved from http://un.info.np/Net/NeoDocs/View/8236

$\mathrm{Wu}$, C. C. (2011). The impact of hospital brand image on service quality, patient satisfaction and loyalty. African Journal of Business Management, 5(12), 48734882. 